\title{
As caatingas
}

\section{NILO BER NARDES}

$\mathrm{D}$ E TAL MODO é variada a paisagem vegetal característica do interior do Nordeste brasileiro que seria preferível referir-se a ela no plural. Dificilmente poderíamos dar uma descrição simples e completa do que comumente chamamos de caatinga sertaneja. Ela é muito vasta, abrangendo estados inteiros ou grande parte de outros. Está submetida, na verdade, a condições pluviométricas distintas e o solo que a recobre apresenta diferenças sensíveis decorrentes da constituição geológica. Euclides da Cunha, ao descrever o cenário áspero em que se desenrolou a grande tragédia sertaneja, reportando-se à área relativamente pequena em que o conhecera, no norte da Bahia, já preferia o emprego da expressão caatinga no plural.

Embora o vocábulo português sertão tenha estado ligado desde os primórdios do povoamento a todas aquelas regiões ainda não povoadas ou ainda mal ocupadas do país, mesmo as que têm ostentado densas selvas tropicais pluviosas, a natureza hostil do interior do Nordeste, dificultando a fixação humana, gerando uma ocupação rarefeita de lento e penoso adensamento, moldando o isolamento das comunidades que só mesmo a era do caminhão veio romper, consagrou o nome do sertão para todo aquele imenso território coberto pelas caatingas. Curioso é que os habitantes das pequenas áreas insuladas dentro das caatingas ou das faixas de caatingas periféricas, melhor beneficiadas pela umidade e mais compactamente povoadas, somente designam sertão aos grandes espaços de solo mais ingrato, onde os animais pastam à solta, os cultivos são mais raros e a população menos numerosa. É como se houvesse uma extraterritorialidade, favorecida pela natureza, que aí se mostra menos ingrata do que em derredor.

A região das caatingas abrange, praticamente, toda a área dos estados do Ceará e do Rio Grande do Norte; quase todo o sudeste do estado do Piauí; a maior parte do este dos estados da Paraíba, de Pernambuco, das Alagoas e de Sergipe; a maior parte de todo o interior da Bahia e até mesmo uma apreciável porção do extremo norte do estado de Minas Gerais. São mais de 800 mil km² de extensão, significando que uma décima parte do território brasileiro é coberto pelas caatingas. Ao norte, elas chegam até a faixa praiana e a oeste e ao sul entram em contato com a região dos campos cerrados, características das nossas regiões centrais. Do lado oriental, porém, seus limites nem sempre são muito nítidos e elas se mesclam 
com as espécies vegetais de florestas mais secas em uma larga tira de transição para a mata higrófila atlântica. Na Paraíba, em Pernambuco e Alagoas essa transição se faz em uma região muito típica, o chamado Agreste, onde em certas partes já se sente bem, na paisagem, a aparência das caatingas.

Geralmente associa-se a ocorrência das caatingas à existência do clima semi-árido que vigora em significativa parte do sertão do Nordeste. Entretanto, o clima semi-árido propriamente dito, aquele que se caracteriza por acentuados índices de aridez, devido às baixas quantidades anuais de chuvas, aliadas a elevadas temperaturas médias anuais, não se verifica senão em uma área bem menor do que a do território já descrito. A grosso modo, pode-se dizer que as caatingas aparecem nas áreas onde os totais anuais de chuva, em termos normais, já estão abaixo de $1.000 \mathrm{~mm}$. Nem por isso se caracteriza ainda o clima semi-árido. Mas dentro da zona mais tipicamente semi-árida, a qual ocupa apenas parte do interior nordestino, lugares há em que não se chega a registrar a metade daquele total de chuvas. Por isso mesmo, há uma tendência entre os geógrafos de distinguir os chamados sertões hipoxerófitos mais chuvosos, daqueles hiperxerófitos, onde é mais acentuada a aridez e as caatingas retratam, em sua fisionomia, nos tipos de plantas que exibem e na própria disposição que as mesmas plantas apresentam, o maior rigor das condições climáticas. A principal área desses sertões mais secos estende-se logo a oeste do planalto alongado da Borborema, em uma faixa que se alonga pelo centro do Rio Grande do Norte, da Paraíba e de Pernambuco, continuando por outra larga faixa ao longo do médio vale do São Francisco, de Paulo Afonso, até o centro da Bahia. O extremo sul dessa faixa é extremamente seco, totalmente impróprio à vida humana nas condições atuais e constitui uma área até hoje despovoada, onde nem mesmo os cangaceiros conseguiram se manter refugiados por muito tempo. Trata-se do trecho que os baianos costumam chamar de raso da Catarina, o mais extenso desses rasos que ocorrem no sertão. Em contrapartida, é exatamente no extremo norte dessa faixa de sertões hiperxerófitos, que existe outra área famosa pelo valor de sua produção algodoeira: o Seridó potiguar.

Todos os naturalistas e fitogeógrafos que estudaram a caatinga sentiram a sua complexidade e o seu caráter extremamente heterogêneo. De início se dizia que a caatinga - a mata (caa) clara (tinga), na língua indígena era uma floresta espinhenta. Nos manuais de língua inglesa ela ainda é freqüentemente assim referida (scrub-forest). Mas nem sempre os seus diversos tipos lembram realmente o porte de uma floresta e nem sempre eles são, na verdade, caracteristicamente espinhentos. Em algumas áreas, com efeito, a predominância das árvores lhe dá um porte que a caracteriza como 
caatinga arbórea. Mas em muitos outros lugares somente ocorre a caatinga arbustiva, ora mais alta, ora mais baixa. O botânico alemão Philip von Luetzelburg, que há mais de 40 anos realizou estudos na região por conta da antiga Inspetoria Federal de Obras Contra as Secas, distinguiu nada menos que 12 tipos de caatingas grupados nas duas categorias descritas, atendendo à freqüência de determinadas plantas e ao aspecto daí resultante. E depois dele muitos dos estudiosos que se aprofundaram na questão apresentaram novas tentativas de classificação, acentuando novos aspectos ainda não apontados.

Aspectos dos mais descritos e, realmente, dos mais característicos são aqueles das caatingas que apresentam um solo raso e cascalhento, onde, durante alguns meses, medram variedades de capim, e o panasco ou o mimoso, conforme o lugar entre as plantas mais altas. Destas, são muito freqüentes os pequenos e grandes arbustos, em geral espinhentos, muitas vezes formando moitas com altura suficiente para cobrir um homem a cavalo. Não é sempre a mesma variedade de arbusto que predomina. A presença da jurema, regularmente alta, sucedendo-se com freqüência, muitas vezes é o primeiro sinal de que estamos entrando em área de caatinga. Também se repetem bastante o pereiro, a caatinga, o pinhão bravo, o marmeleiro, ou ainda, a faveleira, com suas folhas cobertas de espinhos, abundantes no sertão do norte da Bahia e do médio São Francisco.

Acentuando o caráter inóspito da paisagem destacam-se amiúde as cactáceas, recheadas pela água que acumulam, e as bromélias. Os cactus, pela sua freqüência, pelas formas curiosas, muitas vezes de solene aspecto, pela seca, destacam-se na paisagem e estão sempre associados à imagem que comumente se faz das caatingas. Mas há grandes extensões, sobretudo em áreas hipoxerófitas, em que eles são bem pouco freqüentes.

São famosas três espécies: o xique-xique, roliço e se esgalhando encostado ao chão; o facheiro, alto, com seus numerosos ramos apontando para o céu e o celebrado mandacaru, ereto e simples, com uma ou outra ramificação. Há ainda mortos como o quipá ou palmatória de espinhos e o coroa-de-frade, pequena bola rasteira. Das bromélias, a macambira é a espécie mais difundida, mas há certas áreas em que é particularmente numeroso o caroá, muito importante economicamente pois sua fibra se presta à industrialização. Quando o porte arbóreo domina na paisagem, ou mesmo quando árvores ocorrem esparsas, as espécies mais repetidas, entre outras, são o angico, a baraúna, a aroeira, o umbu, a quixabeira, o bonome, ou o juazeiro, de particular significação para os homens e para os animais, por ser a única árvore que conserva sua copa frondosa durante todo o ano. 


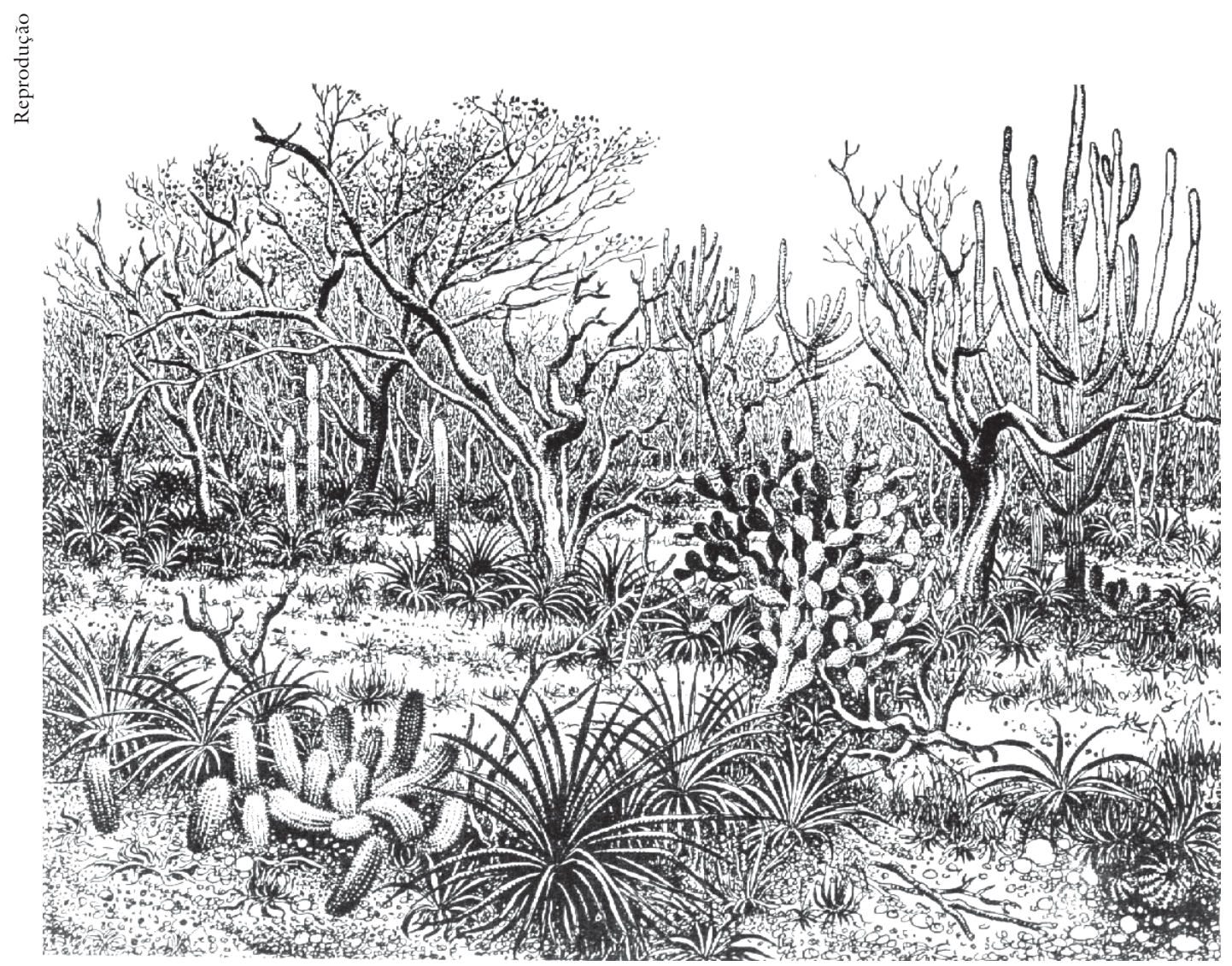

Caatingas - Bico de pena de Percy Lau (1940)

Como assinalamos, não é somente pela freqüência de determinadas plantas que se diferenciam as caatingas. Também a disposição e o arranjo no espaço dos indivíduos vegetais varia. Em muitos trechos, os arbustos se dispõem em moitas ou se dispersam isoladamente deixando espaços abertos por onde a circulação é fácil. Quando assim acontece, a caatinga é muito mais semelhante a estepes arbustivas que ocorrem em outras regiões do globo, e nada tem de uma floresta baixa, como erroneamente se tem generalizado. Em outras áreas os mesmos arbustos estão de tal modo altos e cerrados, formando um compacto emaranhado de galhos finos e espinhentos, que as reses se perdem facilmente e os vaqueiros têm grande dificuldade em vencer barreira tão intrincada. Diferenças da mesma ordem podem ser observadas entre as caatingas que ostentam o porte arbóreo.

Nem sempre os contrastes assinalados se alternam em distâncias relativamente pequenas. Ao longo das extensas rodovias que agora cortam os 
sertões em todos os sentidos, podem se percorrer dezenas de quilômetros em que a paisagem desfila com uma uniformidade monótona e, por vezes, deprimente para o forasteiro. Tal monotonia se acentua com a topografia também uniforme ou suavemente ondulada que caracteriza os grandes plainos sertanejos, apenas interrompidos aqui e ali pelo perfil de uma chapada ou de uma serra que se alça no horizonte ou pela presença de morros e de pequenas cristas insuladas nas rasas superfícies.

Por outro lado, é necessário assinalar, nas planícies justafluviais que se abrem para o litoral norte, tal monotonia é agradavelmente rompida pelo perfil dos extensos carnaubais, onde milhares e milhares de palmeiras de capas originais se juntam, uniformemente e sempre verdes, graças à maior umidade daqueles solos, à maneira de longas galerias. Uma característica biológica é comum às plantas de toda a região das caatingas e dá a marca fundamental da paisagem em toda a parte. É a severa adaptação das espécies vegetais ao rigor da estiagem que se verifica nos sertões. Deve ser lembrado, porém, que varia de região para região a época em que tal fato ocorre.

O período seco, que costuma compreender sensivelmente a metade do ano, via de regra é absoluto, apenas interrompido por escassas e esporádicas pancadas de água, as trovoadas, como chamam os sertanejos em algumas regiões. O período chuvoso que em todo o Nordeste é conhecido sugestivamente como inverno, ocorre em quadras distintas. Na parte norte da região sertaneja, ele se verifica de dezembro a maio (na quadra de verão-outono, digamos). A leste, como uma continuação das chuvas que caem abundantemente no litoral oriental, os meses mais úmidos costumam ocorrer entre março e agosto (outono-inverno). Na parte central e no sul, porém, o regime de chuvas é análogo ao de todo o interior do Brasil e, embora irregularmente, as chuvas costumam cair entre outubronovembro e março (quadra do verão).

Depois de cessadas as chuvas, as plantas ainda conseguem se manter verdes enquanto podem dispor de água do solo, recurso que a acentuada evaporação lhes rouba rapidamente, ou da água que elas mesmas conseguem armazenar, segundo os mais diversos artifícios da natureza, Depois, a necessidade de garantir a sobrevivência faz com que reduzam a transpiração e, embora tenham geralmente as folhas pequenas, elas perdem a folhagem. Daí serem as caatingas modalidades de vegetação tipicamente decíduas, ou seja, de espécies com folhas caducas, que se renovam totalmente a cada ano. O capim rasteiro é o primeiro a morrer na sua parte aérea. Logo depois são os arbustos que se restringem a galhos secos e, finalmente, as árvores acabam também por se desfolhar. 
Vem, então, a estação triste dos sertões, com o solo calcinado, a vegetação reduzida a uma galharia ressequida e acizentada, com a paisagem apenas salpicada pelo verde dos cactus e das bromélias ou, em certos lugares, pelas copas espaçadas dos juazeiros. Em sua maior parte as plantas exibem agora claramente seus troncos retorcidos, seus galhos tortuosos, compondo uma visão atormentadiça.

Depois que o sertanejo colhe as últimas espigas de milho do roçado, cessam quase todas as atividades e a paisagem como que sofre uma paralisação. É a estação morta do sertão, a estação do ócio, quando mesmo os grandes rios já estão reduzidos a poças descontínuas, e os homens e os animais lutam com a carência da água disponível. Nada há a fazer senão esperar o próximo inverno. No final da estação seca até a própria natureza parece extremamente angustiada, contemplando o céu de um azul luminoso, pontilhado por raras e esparsas nuvens. Nem sempre as chuvas se iniciam na época prevista. Seu atraso coloca em todas as mentes a grande pergunta, se realmente virá o inverno naquele ano, se já não se prenuncia uma nova calamidade, como freqüentemente se registra no sertão.

Mas logo que caem firmes e regulares as primeiras chuvas, tudo revive rapidamente. $\mathrm{O}$ panasco, o mimoso, ou outro capim, atapetam imediatamente os espaços abertos, os arbustos como que milagrosamente se cobrem de folhas e as árvores criam novas ramagens. Em breve, as flores mais variadas enfeitam o sertão, num verdadeiro afă da natureza de fazer esquecer a quadra mesquinha. Os rios e riachos passam a correr. Recrudescem as atividades agrícolas e pastoris. Homens e mulheres que foram para outras regiões em busca de trabalho, voltam para os seus roçados. Renascem, também, as esperanças; e o apego do sertanejo pela terra áspera se torna ainda mais arraigado.

A atividade agrícola, acentuando-se com o progressivo aumento da população, transformou, por vezes completamente, a fisionomia original da caatinga naqueles trechos onde as condições de solo e água são mais favoráveis. O que aí se encontra, então, é uma vegetação secundária de capoeiras (caapuera), bem diferente da vegetação primitiva. Este fato levou à fantasiosa idéia, sem nenhum apoio científico, de que as caatingas teriam sido originalmente florestas, em delicado equilíbrio com as condições do meio, que se degradaram pelas repetidas queimadas para o estabelecimento de roçados ou para a melhoria de pastagens nativas. Lembrou-se que os próprios índios teriam desencadeado tal processo, queimando o mato para seus plantios e para desentocar os animais por ocasião de suas grandes caçadas. Na realidade, se em alguns lugares houve profunda transformação pelo 
homem, em muitas áreas, onde o meio é realmente desfavorável, as caatingas se conservam pouco alteradas, quando não intactas, homogêneas, em largas extensões.

As características naturais encontradas pelo colonizador nas caatingas, os espaços livres facilitando o trânsito e as variedades de capim e de arbustos leguminosos favorecendo o pastoreio permitiram, justamente, a desmesurada expansão do povoamento com base no criatório extensivo. Originou-se, assim, o famoso ciclo do gado nordestino, quando, já no século XVII, com base nas áreas mais densamente povoadas nas matas litorâneas do recôncavo baiano ou de Pernambuco, chegaram os currais até o Piauí, o Ceará e mesmo aos confins do norte de Minas Gerais. Com a multiplicação dos engenhos açucareiros nos vales úmidos e férteis do litoral oriental, aumentou a população dos estabelecimentos agrícolas e das aglomerações urbanas. Todo o esforço do desbravamento da mata atlântica era no sentido de ganhar mais terras para a cana. Somente para os animais de trabalho, que moviam as almanjarras e transportavam a cana para os bangüês, ou para os que iam ser imediatamente consumidos, se concebia deixar uma área em pastagens. Desse modo, atendendo às enormes necessidades de abastecimento das populações litorâneas, as fazendas de criatório - nos primeiros tempos conhecidas como currais - foram se multiplicando nas caatingas vizinhas, onde a agricultura comercial era impraticável.

Em nenhuma outra região o povoamento, a conquista do interior, se alastrou tão rapidamente por uma área de tal modo vasta. Processou-se, porém, de modo bastante rarefeito. O sistema tradicional de criação, que ainda perdura na maior parte da região - sendo o do livre pastoreio, bem como a mediocridade forrageira da vegetação nativa - exigiam grandes espaços para a solta do gado. Os pontos de apoio para as fazendas foram as ribeiras, aproveitando o suprimento de água, embora intermitente, aproveitando as margens e os leitos secos para a circulação mais desimpedida. $\mathrm{O}$ São Francisco, a única corrente fluvial permanente em todo sertão, tornou-se famoso como o rio dos currais e, por seus intermédio, também as zonas de mineração do centro vieram a se beneficiar do criatório das caatingas. Além da água, as margens dos rios e riachos ofereceram as terras de maior valor agrícola. Correndo espraiados e abundantes durante a época das chuvas, os cursos de água construíram largos baixios, em que o solo aluvial e a maior umidade da terra, contrastando com os altos (ou centros) de solos secos e pedregosos, favorecem os cultivos. Não raramente são os próprios leitos arenosos que comportam as culturas de vazante, praticadas logo que o fluxo diminui e, depois, corta. Quanto piores as condições do sertão, maior a dependência dos habitantes com relação aos baixios, mais 
rígida é a distribuição da população junto às ribeiras. As propriedades rurais valem pelo tamanho da frente que apresentam junto aos leitos fluviais. Sua grandeza é referida em braças de largura entre as divisórias laterais. Para dentro da caatinga, nas áreas interfluviais, pouco interessa conhecer os limites dos fundos. Aí ficam os terrenos comuns, onde o gado de todos vive em compáscuo, misturado durante quase todo o ano.

Tal forma de pastoreio condicionou a figura do vaqueiro nordestino, com sua característica indumentária de couro que o defende dos gravetos e espinhos, quando rompe a caatinga em busca da rês transviada. Preposto do fazendeiro, muitas vezes ausente, o vaqueiro vai perdendo muito de sua independência e da sua importância na escala social do sertão. $O$ tradicional regime de sorte, por exemplo, verdadeira parceria pastoril na qual uma quarta parte das crias nascidas lhe pertence - o que permitiu a muitos deles se estabelecerem como fazendeiros - vai desaparecendo gradativamente. Para tanto, contribuem as modificações nas condições econômicas, sobretudo a grande valorização que o gado de corte vem tendo nas últimas décadas.

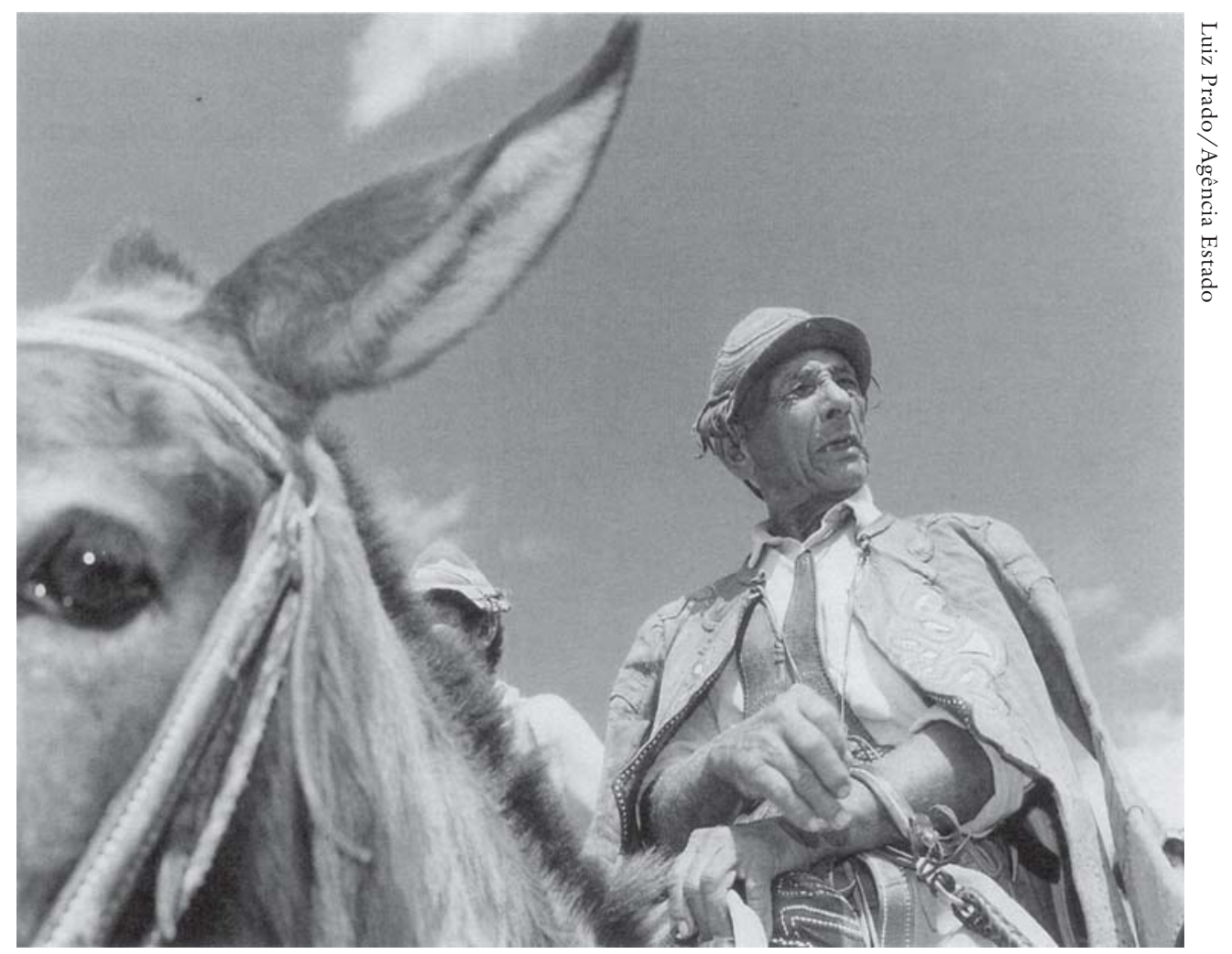

O vaqueiro nordestino é um homem bem relacionado com os peões em amizade e camaradagem. 
Ao contrário da imagem simples que muitas vezes se tem, a agricultura ocupa a massa principal da população das caatingas, população constituída sobretudo por meeiros e rendeiros das fazendas e por pequenos proprietários. As beiradas dos rios, devidamente cercadas, são intensamente cultivadas, mas também as áreas dos centros freqüentemente abrigam roçados esparsos. Nas parcelas cultivadas misturam-se o algodão - produto comercial básico das caatingas - ou a mamona com o milho, o feijão ou a fava. Por toda a parte em que as condições do solo permitem, planta-se também a mandioca que fornece a farinha, mantimento básico na dieta da população sertaneja.

Graças à agricultura, grande parte das caatingas, paradoxalmente, conta com uma população bem mais densa do que muitas das outras regiões brasileiras onde as condições naturais são bem menos ingratas. É realmente delicado, porém, o equilíbrio ecológico a que estão submetidos os sertanejos. Basta que um inverno não chegue, que venha muito atrasado ou com chuvas escassas, para que se declare a calamidade. Periodicamente, após um certo número de anos normais, uma parte das caatingas, conforme o regime de chuvas a que está submetida, tem sofrido a tortura das secas. Algumas delas ficaram na memória de gerações de sertanejos por sua intensidade e duração ou pela extensão da área atingida. Uma ficou lendária, a grande seca do fim do século XVIII que assolou todo o sertão, do Ceará à Bahia, dizimando um terço de todo o rebanho bovino e pondo fim à indústria saladeril do Nordeste, em cuja costa norte (Paraíba, Acaraú, Aracati entre outros pontos) existiam numerosas oficinas para o preparo da carne do Ceará. Por várias ocasiões, desde o período colonial, os reflexos catastróficos das secas perturbaram a vida econômica e social de toda a região nordestina e deixaram as autoridades atarantadas, à procura das medidas mais eficazes a serem postas em prática. Com o elevado aumento da densidade demográfica nos últimos 100 anos, a tragédia veio assumindo vulto cada vez maior, inspirando algumas das mais dramáticas e mais belas páginas de nossa literatura regional.

Alguns lugares do sertão são particularmente favorecidos pela umidade e pelos solos. Constituem, então, verdadeiros oásis durante todo o ano, oferecendo, por outro lado, melhores condições de resistência na ocasião das secas. Por isso mesmo, constituem focos de excepcionais atrativos, fixando uma população bastante numerosa, abrigando parte dos retirantes das caatingas nos anos ruins. Aos lugares mais úmidos, geralmente o nordestino chama brejo. Os altos de algumas serras isoladas são famosos pelo seu verdor: serra do Baturité, no Ceará; serra da Baixa Verde e serra de Tacaratu, em Pernambuco, entre outras, são as mais faladas. Algumas áreas, 
geralmente pela natureza sedimentar de seus terrenos, são propícias ao armazenamento de água e alimentam fontes permanentes, origem de riachos perenes que favorecem o regadio. Importantes são os riachos da Chapada Diamantina, no centro da Bahia. Mas o Cariri cearense é a mais importante, a mais notável de todas essas áreas privilegiadas. Embora não sejam tão úmidos, mas com solos igualmente bons, os sopés das serras e serrotes isolados constituem os tão decantados pés-de-serra, grande atrativo agrícola para as populações das caatingas.

No sertão, de modo geral, com o gado vivendo à solta, as parcelas cultivadas são sempre defendidas pelos pequenos cercados. Mas desde que determinado trecho favoreça o predomínio da atividade agrícola, o contrário se verifica. Então, como toda uma grande área passa a ser dedicada preferencialmente aos plantios, quer pela tradição, quer pelas posturas municipais, ela é defendida por uma cerca de enorme extensão: o travessão, respeitável e respeitado, a divisória de dois domínios culturais na região das caatingas.

Dessa forma, o interior do Nordeste, com as paisagens naturais das caatingas, de aspectos singulares e sugestivos, com suas asperezas e seus encantos que moldam o temperamento do sertanejo, apresenta, por outro lado, cunhos originais decorrentes da atividade humana. É, sem dúvida, a fonte mais rica de tradições e costumes folclóricos em todo o Brasil.

Nilo Bernardes (1922-1991), geógrafo, foi pesquisador do Instituto Brasileira de Geografia e Estatística (IBGE). Foi professor da PUC-RJ e lecionou Geografia no curso de Doutorado em História da Universidade Federal Fluminense (RJ).

Publicado originalmente no $10^{\circ}$ livro das secas, Vingt-Un Rosado e América Rosado (seleção e organização), Coleção Mossoroense, v. CCCIV, 1985, Natal, RN. 